\title{
THE
}

\section{Principals' Perspectives on the Roles of Specialized Literacy Professionals}

Rita M. Bean

Allison Swan Dagen

Jacy Ippolito

Diane Kern

University of Rhode Island, dkern@uri.edu

Follow this and additional works at: https://digitalcommons.uri.edu/education_facpubs

The University of Rhode Island Faculty have made this article openly available.

Please let us know how Open Access to this research benefits you.

This is a pre-publication author manuscript of the final, published article.

Terms of Use

This article is made available under the terms and conditions applicable towards Open Access Policy Articles, as set forth in our Terms of Use.

\section{Citation/Publisher Attribution}

Bean, R.M., Dagen, A.S., Ippolito, J. \& Kern, D. (2018). Principals' perspectives on the roles of specialized literacy professionals. The Elementary School Journal 119(2). 327-350. https://doi.org/10.1086/700280 Available at: https://doi.org/10.1086/700280 
Principals' Perspectives on the Roles of Specialized Literacy Professionals 
Principals have been identified as key leaders of instructional change in their schools; indeed, their leadership has been found to be second only to classroom instruction in its impact on student learning (National Association of Secondary School Principals and National Association of Elementary School Principals, 2013). Researchers have also found principal leadership to be an important factor in school improvement efforts (Bryk, Sebring, Allensworth, Luppescu, \& Easton, 2010; Dinham, 2005; Goldenberg, 2004; Sebring \& Bryk, 2000). Principals set priorities and facilitate the development of shared leadership, creating a culture in which teachers and other professionals are involved in making decisions about literacy programs and instruction. They contribute to school change by encouraging teachers to collaborate in efforts to support literacy improvement initiatives (Berebitsky, Goddard, \& Carlisle, 2014).

Supovitz, Sirinides, and May (2010) identified three categories of principal actions that have an influence on student achievement: setting the mission and goals of the school, focusing on instruction, and developing a culture of trust and collaboration. To develop a culture of collaboration, principals often call on specialized literacy professionals to lead building-based efforts to improve literacy teaching and learning (Author, 2012; International Literacy Association, 2015a; Mangin, 2007; Mangin \& Stoelinga, 2008). Yet, the work of these literacy professionals may differ, depending on contextual factors, principals' knowledge about literacy instruction, specialists' experience, and so on. Given the many different titles used to describe those who function as literacy professionals, we chose to use the definitions in the position statement published by the International Literacy Association, (2015b); they use the term specialized literacy professionals as an overarching or umbrella term for the three roles of reading/literacy specialist, literacy coach, and literacy coordinator/supervisor. 
Although there is research about how specialized literacy professionals function in schools (Author, et al., 2015; Calo, Sturtevant \& Kopfman, 2015; Blamey, Meyer, \& Walpole, 2008 International Literacy Association, 2015a), we know much less about how these professionals interact and collaborate with principals, each other, and with others in the school, to develop and continually refine a literacy program that is effective for all students. As potential literacy leaders, what are the roles and responsibilities of specialized literacy professionals? Further, what are the views of principals about specialized literacy professionals' contribution to the literacy program, its design, implementation, and evaluation?

The specific goals of this survey study were to explore principals' perceptions of the extent to which specialized literacy professionals were involved in leading literacy improvement efforts, the ways in which they enacted those roles, and their interactions with principals that facilitated effective literacy teaching and learning. We asked the following research questions:

1. What categories of specialized literacy professionals (e.g., reading specialists, coaches, literacy coordinators/supervisors) serve in schools participating in a statewide literacy initiative?

2. Which activities do principals report specialized literacy professionals engaging in most often, and which do principals identify as most important?

3. What differences exist between elementary and secondary principals' perceptions of the activities of specialized literacy professionals?

4. In what ways do principals believe these specialized literacy professionals influence literacy instruction and learning in the elementary and secondary schools? 


\section{Theoretical Framework}

The primary theoretical framework that guided our work was that of distributed leadership (Spillane, Halverson, Diamond, 2001; Spillane, 2005; Spillane, 2015). This framework emphasizes the importance of leadership as a product of the interactions of a school's leader and followers in any given situation. Evidence over the past several decades illustrates the possibility and power of distributed leadership in schools, in which various stakeholders have a voice in decision-making (Bryk, Sebring, Allensworth, Luppescu, \& Easton, 2010; Louis, Leithwood, Wahlsrom, \& Anderson; 2010; Spillane, Halverson, \& Diamond, 2001, Supovitz, et al., 2010). Such a perspective goes beyond the notion of multiple leaders and emphasizes "reciprocal interdependency" (Spillane, 2005, p. 146) among these individuals. In other words, school professionals who serve as formal or informal leaders, are influenced by and influence each other. Adopting this framework allowed us to create a survey instrument and to analyze our data with sensitivity to the wide range of ways in which principals might describe the responsibilities they share with specialized literacy professionals in leading literacy teaching and learning activities in schools.

The principal, although important in leading school change, rarely leads alone. In other words, the myth of the principal as a superhero solely responsible for school leadership, is increasingly just that, a myth (Eisold, 1997; Heifetz, Grashow, \& Linsky, 2009). The notion that specialized literacy professionals might also serve as leaders in their schools, and that they may influence and be influenced by the principal, was critical in the design of the questionnaire and in the interpretation of the data. We were especially interested in determining which leadership roles specialized literacy professionals assumed (e.g., leading teacher teams, selecting or 
designing curriculum). We were also interested in investigating how principals interacted with these professionals, not only supporting them as leaders, but also learning from them.

\section{Review of Related Research and Literature}

We reviewed two distinct bodies of literature to contextualize our research. The first body of research focuses on the ways in which principals and literacy professionals interact to facilitate literacy learning in schools. The second body of research describes the ways in which specialized literacy professionals functioned in schools and the major changes in roles and responsibilities that have led to their current role as literacy leaders.

\section{Interactions Between Principals and Specialized Literacy Professionals}

In the past decade, several research studies have addressed questions about the interaction between principals and the work of specialized literacy professionals, especially literacy coaches. Results indicated that principals' actions and support for coaching were important for its success in improving classroom instruction (Camburn, Kimball, \& Lowenhaupt, 2008; Mangin 2007; Mangin \& Stoelinga, 2008). Matsumura, Sartoris, Bickel, and Garnier (2009), in their study of a coaching program in elementary schools, found that there was a relationship between principals' leadership actions and the frequency of teachers' interactions with literacy coaches. Specifically, teachers engaged with coaches more frequently in schools where principals actively participated in the coaching program, publicly endorsed the coach as a source of expertise, and shared views about teaching with coaches.

Author (2012) studied five elementary schools, identified as successful implementers of a Response to Intervention (RTI) framework, to learn more about how various personnel, including literacy professionals, teachers, and principals, functioned in their roles. They found that principals in these schools were actively involved as instructional leaders: "being on the 
sidelines was not an option" (p. 497). Principals served in an important role, "promoting a riskfree environment, leading the effort in establishing norms for collaboration, and facilitating shared responsibility and accountability" (p. 497). Reading specialists and coaches worked as a team to discuss data results and make decisions about grouping and instruction. Principals also indicated that both reading specialists and literacy coaches managed the RTI initiative and provided essential information to them about assessment and instruction. Thus, the principals' job was to facilitate the work of specialized literacy professionals and teachers - to empower them as literacy leaders in the building.

Likewise, Carlisle and Berebitsky (2011), in their study of professional development comparing elementary schools with coaching versus those without coaching, found that support of principals contributed to the instructional efforts of coaches. Author (2015) studied the sustainability of Reading First in elementary schools in two states; the results identified coaching as a beneficial approach to providing job-embedded professional learning experiences for teachers. They also found that principal leadership, support, and buy-in were important factors that contributed to successful implementation and sustainability of the Reading First program.

There is less research about principal interactions with specialized literacy professionals at secondary levels, although in the past decade, researchers have begun investigating the work of literacy coaches in middle and high school settings (Blamey, Meyer, \& Walpole, 2008; Marsh, et al., 2008; Rush, 2013; Smith, 2007). Across these studies, there is evidence of the importance of principal support for coaching success and a recognition of the need for coaches at secondary levels to develop a strong relationship with principals. However, there is little detailed information about the nature of these relationships. 
The research supports the contributions that both principals and literacy professionals make to the development of a culture of shared or distributed leadership. However, given that instructional leadership is often studied from multiple perspectives, less is known about the specific ways in which these leaders work together. Neumerski (2013) analyzed three distinct bodies of research: principal leadership, teacher leadership, and leadership related to instructional coaching. She suggests that these "disconnected literatures, each concentrating on different leadership 'roles' seems to move the field further from determining how various leaders lead" (p. 312). In her study, she highlighted the importance of learning more about the interactions among each of these instructional leaders. In other words, how does the work of one group facilitate or impede the work of the other?

An important aspect of better understanding various interactions among literacy leaders in schools is making sense of the shifting roles of specialized literacy professionals over time. Below, we provide a description of how the roles of specialized literacy professionals have evolved from primarily serving as "remedial reading teachers" working in isolation to literacy leaders in schools who work with both students and adults.

\section{The Evolving Roles of Specialized Literacy Professionals}

Reading specialists, perhaps the first and still most common of all the specialized literacy professional positions, have played key roles in U.S. schools since the 1960s, yet their roles have changed significantly over time. Initially, reading specialists functioned as remedial reading teachers, responsible for teaching students with reading difficulties in pull-out settings. However, over time, their roles changed; although they still worked with students, they more frequently taught in the classroom alongside classroom teachers. This shift allowed reading specialists to 
provide instruction that was more congruent with what students received in their classrooms

(Allington \& Shake, 1986; Kennedy, Birman, \& Demaline, 1986; Walp \& Walmsley, 1989).

Given this role change in the late 1990s from pull-out to in-class instruction, the International Reading Association (now the International Literacy Association [ILA]) appointed a commission to summarize research about the role (Author, 2001) and investigate the ways in which reading specialists functioned in schools across the country (Author, 2002). As part of the commission's work, Author (2003) also investigated the ways in which reading specialists functioned in exemplary schools. This entire set of papers indicated that: (a) reading specialists have multiple roles; (b) there was much more emphasis on working collaboratively with teachers, with reading specialists serving as a resource for teachers; and (c) principals in exemplary schools viewed reading specialists as having an important impact on the success of the literacy program.

In the early 2000s, with the passage of the No Child Left Behind Act (NCLBA, P.L. 107110) and its programmatic arm, Reading First, schools began to employ reading or literacy coaches responsible for working with teachers to assist them in the implementation of the reading program as dictated by that legislation. Frequently, those who had been serving as reading specialists were assigned to this new position and asked to assume more of a teacheroriented role. Later, as states and districts adopted and adapted the Common Core State Standards (NGA/CCSSO, 2010), with its emphasis on literacy as an important element of instruction in the academic disciplines, especially in upper elementary, middle, and high schools, coaches were hired to work with teachers to support them in their efforts to implement literacy across the curriculum. 
In 2003, the Standards for Reading Professionals-Revised 2003 (IRA, 2003) introduced a new role, that of reading specialist/literacy coach. This role was again identified in the Standards for Reading Professionals- Revised 2010 (IRA, 2010); the writers of the 2010 Standards acknowledged that a reading specialist/literacy coach "may have a specific focus ... such as serving as a teacher for students experiencing reading difficulties, as a reading or literacy coach, as a coordinator of reading and writing programs ... [or] several combinations of these roles" (p. 49). In other words, context and district decisions influenced the tasks and responsibilities of these professionals. Moreover, by 2010 there seemed to be widespread recognition that these literacy professionals would often assume a leadership role. Similarly, Galloway and Lesaux (2014), in their synthesis of research about the roles of the reading specialist, also found that these professionals did much more than provide instruction to struggling readers. Reading specialists analyzed data to guide instruction, addressed the needs of all students at all levels, and served as a resource or educator of teachers, all of which required them to assume a leadership role in schools.

Given these changes in roles between 2002 and 2015, a second national study was conducted (Author, 2015) to investigate the degree to which there were differences in how various specialized literacy professionals functioned, given new titles and possibly new responsibilities. Results of the 2015 study, in which over 2,500 respondents representing every U.S. state replied to the questionnaire, indicated the presence of distinct role-groups involved with literacy work in U.S. schools and differences in how these professionals fulfilled their roles. Literacy coaches tended to work more with teachers while reading teacher/interventionists focused on teaching students. Literacy supervisors, small in number, tended to have school or 
districtwide coordination roles. Those who self-identified as reading specialists varied the most in role-expectations, although working with students was a primary role.

Another important finding of the national study (Author, 2015) was that, across all roles, respondents identified the importance of being able to work with adults, with $89 \%$ indicating that they in some way collaborated with, coached, or supported teachers. Their responsibilities required them to serve as leaders, working collaboratively with administrators and teachers. When asked to identify factors that contributed to their success, they mentioned the need for principal support and understanding of their role. The findings of this national study served as the foundation for a position statement (ILA, 2015b) clarifying the distinctions among three specific roles of reading/literacy specialist, literacy coach, and literacy coordinator/supervisor.

Together, these two bodies of literature suggest strongly that principal support is critical if specialized literacy professionals are to be successful in their multiple and evolving roles in schools. Further, there is evidence that specialized literacy professionals serve as leaders in schools. Yet, there is a need for more information in terms of how the principal perceives the role of each of the specialized literacy professionals, and how these professionals contribute to successful teaching and learning. Such information could support the development of national standards and preparation programs for principals and specialized literacy professionals, as well as informing the ways that these professionals enact their roles in schools.

\section{Method}

\section{Study Context}

In 2012, Pennsylvania was one of six states that received funding via the federal Striving Readers grant to improve literacy outcomes for all students. The five-year grant was awarded to support the state's comprehensive approach to improving literacy outcomes for all children- 
birth through grade 12. Pennsylvania's initiative, Keystones to Opportunity (KtO), supported programs that advanced literacy skills through professional development, screening and assessment, targeted interventions for students reading below grade level, and research-based methods of improving classroom instruction and practice. The competitive grant required districts to submit a proposal in which they included the results of a needs assessment and a plan for improving literacy in their district. The Pennsylvania Department of Education made grant awards to fifty-eight districts in April 2012, and it was expected that they would receive funding for a five-year period. Districts were to identify multiple approaches to achieving the goals of the grant and could use funds to employ literacy coaches or other specialized literacy personnel to work with students and/or teachers. Principals were identified as key leaders who were expected to participate in professional development sessions as a means of understanding this literacy initiative. These participating districts, although demographically diverse, also provided a comparable context that enabled us to answer our research questions about the role of specialized literacy professionals and their interactions with principals of the schools in which they worked.

\section{Development of Questionnaire}

The authors of this article reviewed previous survey research about the roles and responsibilities of reading specialists and literacy coaches (Author, 2009, 2015; Coburn \& Woulfin, 2012), modified questions from existing protocols and developed new questions that were more specific to the nature of the interactions between specialized literacy professionals and principals. An initial draft of a 50-item questionnaire was piloted in the spring of 2016 with 31 principals known to the authors of this paper, across four states. Individuals who responded commented positively about the content but were less enthusiastic about the length of the survey and the time it took them to complete it. After deleting items and revising those about which 
there were questions, we sent the second draft in fall of 2016 to principals from award winning schools across four states.

After each pilot and data collection cycle, we discussed the meaning of each question, especially terminology related to roles and responsibilities of specialized literacy professionals, and how these questions might be interpreted and answered by the principal. Our final questionnaire, the version used with the population described in this paper, was more focused and specifically supported the research questions. It consisted of 32 questions, mostly forcedchoice, or Likert-scale items; several items provided opportunities for principals to elaborate on their answer, should they choose to do so.

To clarify what we meant by specialized literacy professionals, we defined the term in our initial question and asked principals to identify whether they had any of the following professionals in their schools: reading/literacy specialists, coaches, school-based reading/ literacy coordinators/supervisors, and other. We listed several titles for the position of coach (e.g., reading/literacy/academic/instructional), given the differences in titles across districts. Principals who had both reading/literacy specialists and coaches in their schools were asked to complete the same set of questions for each role. We chose not to ask principals to complete that set of questions for literacy coordinators/supervisors, given results from the national study (2015), which indicated that this role was not present in many schools.

This questionnaire was designed so that participants could complete it in approximately 15 minutes. We used the online tool SurveyGizmo (https://www.surveygizmo.com/) to host and deliver our questionnaire, as it provided the tools needed (e.g., skip-logic, a wide range of item types, etc.) to answer questions. SurveyGizmo was also easy for participants to use and visually 
simple. A copy of the questionnaire can be accessed at https://tinyurl.com/litleadersurvey

\section{Study Participants}

In 2017, the director of the Keystones to Opportunity (KtO) Grant in Pennsylvania approved our request to send a survey to principals of the $238 \mathrm{KtO}$ schools about the numbers of specialized literacy professionals in their schools, the responsibilities of these professionals, and the interactions between principals and these professionals. We emphasized the value that the results would provide grant leaders, giving them detailed information about the role of the specialized literacy professionals in schools and their interactions with principals as a means of providing possible policy implications for districts and the state.

The director sent a survey link, created using SurveyGizmo, via email to these principals. When participants opened the email link, they were presented with an informed consent page including a description of the project, the voluntary nature of participation, assuredness of confidentiality of participants' identities, and researcher contact information, should they have questions. Participants were asked to complete the questionnaire, with all data being delivered electronically directly to the authors of this paper via SurveyGizmo.

We received responses from 196 schools for an initial 82\% return rate. In a first pass at the data, we purged all incomplete responses $(n=36)$, which reduced the sample to 160 schools (67\% of the total $\mathrm{KtO}$ population). In a second round of data cleansing, we shifted our focus to "who" completed the survey. While the vast majority of our responses came directly from principals, other responders $(n=44)$ included assistant principals $(n=28)$; district-level administrators $(n=11)$; and a small group $(n=5)$ of other district level administrators such as a federal program coordinator, a supervisor of special education, and a pre-K coordinator. Given our desire to focus exclusively on the perceptions of school principals, we eliminated the 
responses of the 44 administrators who may have had a different relationship than principals with literacy professionals. After removing these 44 data files, our sample size was reduced to 116.

Lastly, to understand any differences between elementary and secondary principals' perceptions of the roles of specialized literacy professionals, we shifted our focus to the level of the schools. In the survey, principals were asked to identify school level from five options: pre$\mathrm{K} /$ primary, elementary, middle, high, or other. Using the sample of 116 principal surveys received, we recoded and classified school level into one of two categories: (1) elementary ( $n=69$ ), which included 62 elementary schools and seven schools identified as pre-K/primary, or (2) secondary $(n=40)$, which included 15 middle and 20 high schools. Seven schools were not recoded because the responders left the school level field blank or the school level spanned across both categories (e.g., K-12); these participants were not included in this sample. From this new sample of 109 principals, six principals' responses (one elementary and five secondary) were also eliminated as they indicated there were no specialized literacy professionals working in their schools. In other words, 99 percent of the elementary schools and 88 percent of the secondary schools in this sample had at least one specialized literacy professional.

The final sample for analyses included 103 schools (elementary=68; secondary=35) or $43 \%$ of the total $\mathrm{KtO}$ population $(N=238)$. As represented in Table 1, the 103 schools spanned the state and represented diverse settings with about $25 \%$ of the schools representing rural locations $(n=27)$ and $30 \%(n=31)$ representing urban or suburban with urban characteristics. Fifty-three percent ( $n=55)$ of the 103 schools were identified as having $50 \%$ or more of their students eligible for free and reduced lunch. Additionally, 71 principals (69\%) identified their schools as Title I. Principals in this study represented a range of administrative experience with the majority (49\%) serving in the role for $2-5$ years. 


\section{>>Insert Table $1<<<$}

\section{Data Analyses}

To analyze the data, we calculated frequency distributions for the 103 principal responses to forced-choice or Likert-scale items; we also did cross tabulations to investigate the differences (1) in how principals distinguished between the roles of reading/literacy specialists and literacy coaches and (2) the differences in how elementary and secondary principals viewed these roles. We carried out chi-square tests on survey items focusing on frequency of engagement in specific activities to determine if there were significant differences in how the principals perceived the work of the specialized literacy professionals. Specifically, we compared the activities principals identified as "often" against all other frequency options (i.e., sometimes, rarely, never). Given the large number of items (activities) being compared, a Bonferroni correction was calculated, and $p$-value adjusted $(p<.006)$. The open-ended responses from principals were not analyzed for this specific paper, as they were few in number and did not provide additional information not already gleaned from the quantitative data.

\section{Results}

Below we discuss the results for each of the study's research questions, providing summaries of data and discussing key findings. We also present the results of the statistical analyses, summarized in a series of tables.

\section{Categories of Specialized Literacy Professionals in These Schools}

In Table 2, the distribution of specialized literacy professionals by both school level and role is presented. There were approximately the same percentage of reading/literacy specialists as coaches in these 103 schools with 74 of all 103 principals (72\%) reporting a reading/literacy specialist on staff and 77 of the 103 principals (75\%) reporting a coach in their schools. An 
analysis of the data by level, however, indicates that there were proportionally more schools with reading specialists at the elementary level $(59 / 68,86 \%)$ than at the secondary level $(15 / 35,42 \%)$. Conversely, a slightly higher percentage of secondary schools employed coaches, with coaches working in 28 of 35 secondary schools (80\%) as compared to 49 coaches in 68 elementary schools (72\%). Furthermore, 42 of the 68 elementary schools (62\%) and 9 of the 35 secondary schools (26\%) reported having both a reading/literacy specialist and coach. Similar to the national study (Author, 2015), there were only a few literacy coordinators/supervisors $(n=9)$ in these schools. However, given that all schools with literacy coordinators/supervisors also had reading/literacy specialists or coaches, these schools were included in the analysis.

>> Insert Table $2<<<$

\section{Areas of Engagement and Perceived Importance of Specialized Literacy Professionals}

One of the major purposes of this survey was to determine how specialized literacy professionals functioned in their schools; that is, in which activities did they engage? We presented the principals with a list of commonly reported activities, representing the work of specialized literacy professionals with students and with teachers. We asked the principals to indicate how frequently these professionals engaged in these activities (i.e., never, rarely, sometimes, or often). Principals first responded to this list for reading/literacy specialists and then repeated the process if there was a coach in that school. Seventy-four principals responded to the list of activities about the reading/literacy specialists in their schools, while 77 principals responded to the list of activities about literacy coaches. In Table 3, we summarize the activities, as reported by these principals, that reading/literacy specialists and coaches participated in often.

>> Insert Table $3<<<$

Results of the Chi-square tests comparing the activities principals identified as "often" 
against all other frequency options (i.e., sometimes, rarely, never) indicated several significant differences, with principals reporting that reading/literacy specialists instructed students more frequently than coaches, and coaches more often helping teachers understand data, co-plan and co-teach. These results are corroborative and not surprising, given the existing literature and previous findings about the primary distinctions between these two roles (Author, 2015; International Literacy Association, 2015a). In other words, there were distinctive differences in how these professionals functioned, which has implications for how they are prepared and the qualifications that districts might use in selecting them for their positions.

Other observable data trends across the entire sample, although not significant, revealed that both groups of specialized literacy professionals were engaged in many different activities with teachers and students, albeit with differences in extent of engagement. As indicated in Table 3 , over $40 \%$ of the 103 principals reported both reading/literacy specialists and coaches had instructional (specialists $=70 \%$; coaches $=43 \%)$ and assessment responsibilities ( coaches $=49 \%$ ). Principals also reported that slightly over $30 \%$ of both reading/literacy specialists and coaches were engaged often in providing professional learning and development for teachers. Both coaches (49\%) and specialists (32\%) were reported as having coaching responsibilities. Likewise, principals reported coaches (39\%) and specialists (22\%) were involved with the principal in leading the literacy program. Finally, as reported by principals, neither group was engaged to any great extent in supporting teachers in the academic disciplines $($ specialists $=10 \%$; coaches $=14 \%)$.

Principals were then presented with the same list of activities and asked to identify the top three they felt were most important to improving and supporting literacy teaching and learning in their schools. Principals most frequently identified the following as the most 
important activities of reading/literacy specialists in their schools: instructing students (88\%), helping teachers understand data (62\%), and assessing students (59\%). These three responsibilities were all related to direct work with students or with helping teachers understand how to use data to facilitate student learning. When identifying the most important responsibilities for coaches, principals identified the following top responsibilities: coaching teachers $(77 \%)$, helping teachers understand data (57\%), and providing professional learning opportunities for groups of teachers $(60 \%)$. These three activities centered directly on coaches' work with teachers. In other words, principals had different perceptions about which activities were most important for reading/literacy specialists as compared with coaches, and their views are consistent with the distinctions made in the ILA position statement (ILA, 2015b) about the differences in roles. The only overlap, helping teachers understand how to use data, is a good example of what might be considered productive overlap in the responsibilities of professionals holding these positions. Moreover, the emphasis on helping teachers understand data is a leadership task, one that the principals viewed as an important role for these professionals, both reading/literacy specialists and coaches.

\section{Differences in Activities of Elementary and Secondary Reading/Literacy Specialists and}

\section{Coaches}

To determine differences between the responsibilities of reading/literacy specialists and coaches in elementary and secondary schools, we disaggregated the survey findings by position and school level and calculated chi-square tests for significance.

Reading/literacy specialists. Table 4 represents the responsibilities principals indicated reading/literacy specialists engaged in often, disaggregated by school level. Based on the chisquare test analyses, there were no statistically significant differences between elementary and 
secondary levels in activities carried out often by reading/literacy specialists. between the elementary and secondary levels. That noted, the difference in numbers of reading/literacy professionals, with four times as many principals reporting the presence of reading/literacy specialists at the elementary level than at the secondary level, may have had an influence on the statistical findings.

Overall patterns in the analyses point to reading/literacy specialists working with multiple stakeholders (students, teachers, and administrators) across both elementary and secondary school levels. Observable data trends in this sample of reading/literacy specialists indicated that at both school levels, they worked directly and often, instructing and assessing students. As displayed in Table 4, reading/literacy specialists at both elementary and secondary school levels also functioned similarly and often in their work with teachers, specifically when coaching, coplanning, and co-teaching. Finally, $25 \%$ or fewer of principals reported reading/literacy specialists across school levels worked often with the them to organize/lead the literacy program. In other words, neither elementary nor secondary specialists were involved to any great extent in this activity. Although reading/literacy specialists at both levels supported teachers in the academic disciplines, principals did not view these activities as occurring very often (20\% or fewer principals reported this). Principals reported some larger differences between the activities of elementary and secondary reading/literacy specialists, with those at the secondary level more involved with helping teachers understand data, while those at the elementary level more often engaged in providing professional learning for groups of teachers.

$$
\text { >> Insert Table } 4<<<
$$

Coaches. Table 5 illustrates principal responses on the frequency (i.e., often) of activities for coaches, disaggregated by school level. Chi-square test results indicated no statistically 
significant differences between those activities carried out often by coaches at elementary and secondary levels. In this sample, twice as many principals at the elementary level than at the secondary level reported the presence of coaches, which may have influenced the findings.

The activities that both elementary and secondary coaches participated in most often (reported by $50 \%$ or more of principals) were those of coaching, co-planning, co-teaching, and helping teachers understand data. These are activities expected of coaches and suggest that these professionals were viewed as responsible for supporting and guiding teacher learning. Coaches at both elementary and secondary levels were also reported to often be involved in assessing students. Given principals" identification of "helping teachers understand data" as one of the three most important responsibilities of specialized literacy professionals and the emphasis on assessment in the Striving Readers grant, this focus on assessment was expected. Elementary (24\%) and secondary (30\%) principals also reported that coaches were involved in supporting teachers in the academic disciplines, but to a lesser degree than other activities.

Generally, coaches functioned similarly and often across grade levels in working with the principal to organize and lead the literacy program (elementary $=37 \%$; secondary $=42 \%$ ). There were slight differences in the responses of principals to the activity, "Providing professional learning for groups of teachers," with elementary principals (36\%) viewing coaches as participating more often in that activity than secondary principals (23\%). Again, principals reported this activity as one of the three most important ones for coaches.

$$
\text { >>Insert Table } 5<<<
$$

In sum, the findings of this study, which suggest more similarities than differences in the activities of specialized literacy professionals, both reading/literacy specialists and coaches across school levels, seem to indicate that differences in responsibilities may be more a matter of 
degree than of fundamental difference (Author, 2012). That is, the broad nature of the activities in which these professionals are involved is similar. However, future research and analyses of specific factors that influence the work of these professionals at elementary and secondary levels might identify some substantive differences. Hypothesized factors that might contribute to these differences include: heavy emphasis on content, literacy needs of elementary versus adolescent students, classroom teachers' preparation to address literacy needs, size and number of teachers and students in the school. Again, future research may seek to disentangle these factors further.

\section{Influence of Specialized Literacy Professionals on the School Literacy Program}

We also sought to understand ways that specialized literacy professionals influenced various aspects of literacy teaching and learning. To address this question, we asked principals to respond to several questions: (1) factors, including the work of the specialized literacy professionals, that contributed to the school's success; (2) ways in which specialized literacy professionals influenced literacy programs; and (3) how the principal and specialized literacy professionals collaborated in decision making.

To learn more about principals' perceptions of their own school's success, we presented a list of ten items and asked principals to select the items that most contributed to their school's literacy success. Across the 103 principals who replied to this prompt, the top four responses most frequently identified as central to the success of the literacy program included: (1) grant funding that supports a focus on literacy (80\%), (2) a well-developed literacy program (73\%), (3) teachers' professional learning (73\%), and (4) the work of specialized literacy professionals $(64 \%)$.

Given that principals could select all that apply, other factors were also identified as important. In rank order, they included: (5) integration of literacy in the disciplines (54\%); (6) 
change in the culture/environment of the school from "isolation" to "school as a place of learning" (49\%); (7) application and use of technology to enhance literacy instruction (46\%); (8) stability of faculty / low turnover (33\%); (9) stability of principal / low turnover (30\%); and (10) family and community engagement (18\%).

Grant funding, which provided the resources necessary to make changes in the KtO schools' literacy programs, was identified most frequently as a factor influencing school literacy success. Many of the other factors focused on the importance of developing a comprehensive literacy program, also a goal of the funding grant, and it appears principals recognized the work of specialized literary professionals in leading efforts to develop such a program. Both elementary and secondary principals appeared to value the work of the specialized literacy professionals, with 46 of 68 elementary principals (68\%) and 20 of 35 secondary principals (57\%) identifying their presence as contributing to their school's literacy success.

Principals were then asked to identify the specific ways in which specialized literacy professionals influenced literacy learning. In other words, did specialized literacy professionals have an impact on the achievement of students as well as the practices of teachers? Table 6 summarizes these findings. Over $80 \%$ of the principals across elementary and secondary levels reported that specialized literacy professionals had a "moderate" to "major influence" in improving literacy achievement, affecting classroom practices, creating a culture of collaboration, and creating a vision for literacy teaching and learning. As reported by principals, specialized literacy professionals at the elementary level were viewed as having more of an influence on closing the achievement gap than those at the secondary level, although both were rated as highly influential (elementary $=88 \%$; secondary $=77 \%$ ). Both groups were reported as having less of an influence on building and maintaining school/community partnerships, with 
specialized literacy professionals at the secondary level (43\%) having even less influence than elementary specialized literacy professionals (74\%). This finding may reflect the fact that there often tends to be much more parent and community involvement at the elementary than secondary level. What appears significant is that principals valued the presence of specialized literacy professionals in schools, identifying them as having an important influence on factors affecting teaching and learning, specifically improving student literacy achievement. >> Insert Table $6<<<$

Finally, in these schools, 63 of 103 principals $(61 \%)$ indicated they had school-wide literacy leadership teams that focused on many issues related to school improvement (e.g., literacy curriculum and instruction, student assessment measures, teacher professional learning, and developing a vision for literacy teaching and learning). When principals were asked to describe the ways in which decisions were made in schools, relative to the work of the specialized literacy professionals, slightly more than half of the elementary (54\%) and secondary (51\%) principals indicated that "the staff and I work together as a team to make decisions about the literacy program, including programs, materials and implementation.” A slightly smaller percentage of the elementary (25\%) and secondary (37\%) principals indicated they relied on specialized literacy professionals to provide them with information and insights about the literacy program and then used their recommendations to make their decisions. Only 10 percent indicated decisions were made by the district, and less than $3 \%$ said they made decisions about the literacy program alone and had specialized literacy professionals implement those decisions. In other words, more than half of the principals' responses indicated they were involved in developing a school climate that provided for distributed leadership in which specialized literary professionals and principals worked together to make key decisions about literacy. A smaller 
subset of principals acknowledged that they were learning from and being influenced by the knowledge and expertise of literacy professionals in making decisions about the literacy program.

\section{Discussion}

In this discussion section, we first describe in more depth the findings of our study and the ways in which they mirror or diverge from recent past studies of the roles of reading/literacy specialists and coaches in schools. We then outline broad implications of these findings for researchers, policy makers, and for those who prepare and employ these professionals. We conclude by identifying the limitations of the study.

\section{Making Sense of Study Findings}

This study identifies three important findings related to principals' perceptions of the roles of specialized literacy professionals: (1) the value of their presence in schools; (2) the distinctions and overlaps in roles of reading/literacy specialists and coaches; and (3) the lack of clear-cut differences between the roles of specialized literacy professionals at the elementary and secondary levels. Below we discuss these three major findings and relate them to those of other recent studies.

Presence of specialized literacy professionals in schools. Findings from this study suggest that principals in both elementary and secondary schools valued the work of specialized literacy professionals. Indeed, the fact that a specialized literacy professional was present in 103 of the $109(94 \%)$ schools whose principals completed the questionnaire, is an indicator that many school leaders viewed these professionals as being important to the development and management of schoolwide literacy programs. Principals appeared to support a distributed leadership framework (Louis, et al., 2010; Spillane, et al., 2001; Supovitz, et al, 2010), indicating 
that they interacted in a collaborative manner with specialized literacy professionals and other staff, either working as a team to develop and implement their literacy programs, or by acknowledging and using the recommendations made by these professionals.

Further, across grade levels, most principals reported that literacy specialists and literacy coaches had a moderate to major influence on various factors related to the improvement of the literacy program. This finding is similar to that of the Author (2003) study in which principals indicated that reading specialists had a major influence on reading achievement in the schools. While it is challenging to measure the impact of these professionals on teacher and student learning, given the many possible factors that influence both, the fact that principals viewed specialized literacy professionals as contributing to the success of the overall literacy program was a positive indicator of the importance of their presence in schools.

Similarities and differences in roles of reading/literacy specialists and coaches. Over the past 20 years, those who prepare specialized literacy professionals, and researchers interested in the role of these professionals, have been attempting to disentangle the role of the reading specialist from that of the literacy coach. As mentioned in the review of literature, researchers and educators have tended to focus on the reading specialist as serving multiple or dual roles (Dole, Liang, Watkins \& Wiggins, 2006; IRA, 2010; Snow, Burns \& Griffin, 1998; Walpole \& Blamey, 2008). However, questions have arisen about whether this is one role with multiple and diverse responsibilities or two distinct roles. More specifically, can individuals be prepared or even expected to assume both teaching and coaching responsibilities? According to Walpole and McKenna (2012), working with adults requires a different and more complicated set of skills than working with students. They recommended that individuals study to be a reading specialist, 
gain experience in that role, and then return for future study about adult learning, professional learning, and leadership in order to function as a coach. .

The results of the current study which indicate that principals viewed reading/literacy specialists as working primarily with students and coaches as working primarily with teachers are consistent with the results of the national study (Author, 2015). These findings also provide additional support for the separation of the two roles as described in the Standards for the Preparation of Literacy Professionals 2017 (Standards 2017) (ILA, 2018).

At the same time, in both this study and in the Standards 2017, there is an acknowledgement that, in schools, there may be overlap in expectations. For example, in this study, $25 \%$ or more of the principals indicated reading/literacy specialists also provided professional learning for teachers, co-planned and co-taught with classroom teachers, and even coached teachers. Indeed, intervention initiatives such as 3-tier instruction and RTI require today's reading specialists to collaborate not only with teachers, but also with allied professionals such as special educators and psychologists (Author, 2012).

Moreover, although coaches were viewed by principals as having a primary role of facilitating teacher learning, specifically, coaching, co-planning, co-teaching, and helping teachers understand data, they were also viewed by slightly more than $40 \%$ of the principals as having frequent direct assessment and instructional responsibilities with students. In other words, literacy coaches would benefit from an understanding of literacy assessment and instruction; that knowledge would enable them to work directly with students, if required, and also to have the credibility to influence the literacy instructional practices of teachers.

This leads us to conclude that schools often make their own idiosyncratic decisions about these roles, with principals making decisions about whether the literacy professional should 
function more like a reading/literacy specialist or coach. Moreover, when a school has only one specialized literacy professional, that individual by necessity may need to assume both instructional and coaching responsibilities. We argue that there is room for productive overlap, in which both specialists and coaches should be providing targeted professional learning or assessing students. At the same time, we believe that by "sharpening . . . this terminology" (Galloway \& Lesaux. 2014, p. 524) and distinguishing between the two roles, we would be better able to prepare these professionals, and assist them and the districts that employ them in having a better understanding of the expectations of the roles.

Moreover, we wonder whether some of the inconsistent findings in other studies about the effects of specialized literacy professionals on teaching practices or student learning might be related to the inconsistency in what these professionals are doing in schools. Perhaps, there is not enough opportunity to focus; rather, they are doing a little of everything. Because of this overlap in expectations, we see the continuing need for professionals in both roles to have the knowledge and skills of literacy leadership, that is, to understand how adults learn, how to communicate effectively, and how to serve as a leader in the school (Author, 2017; ILA, 2018).

Elementary versus secondary: Differences and similarities. One of the goals of this study was to investigate whether professionals at the elementary and secondary levels were functioning differently, given the context, preparation of teachers, and focus of instruction at these two levels. In this study, we did find significant differences in the perceived roles and responsibilities of specialists and coaches. However, when we compared elementary specialists with secondary specialists, and elementary coaches with secondary coaches, we found few differences in perceived roles and impact. In other words, while the differences between specialists and coaches seemed to be meaningful to principals, elementary and secondary 
principals reported the work of reading specialists to be largely the same across levels, and the work of coaches to be largely the same across levels.

Again, this finding appears to support the notion that differences in elementary versus secondary work for literacy specialists (Author, 2009) and coaches (Author, 2012) may be more a matter of degree than of fundamental differences in the work. We acknowledge, however, that the content of coaching might differ (e.g., secondary coaches must necessarily focus more on content-area and disciplinary literacy instruction than would coaches in the elementary grades [IRA, 2006]). However, this secondary coaching work still focuses primarily on direct service with teachers, one-on-one, in small groups, and whole-school—not direct service with students.

Interestingly, and perhaps reflective of the relatively smaller number of specialists and coaches at the secondary level, principals in this study reported less attention being paid to supporting teachers and students in disciplinary literacy teaching and learning work. Given the focus on literacy across the curriculum, this finding is somewhat surprising and disturbing. Perhaps a vision for how to gradually increase disciplinary literacy instruction across K-12 grades needs to be introduced and acted upon. Further research may shed more light on this question.

\section{The Need for Further Research on Literacy Leadership}

The findings of this study are compelling in that they raise questions worth further investigation. First, future research might assist in developing a deeper understanding of and disentangle the exact ways in which principals depend upon and support specialists and coaches. For instance, the finding that specialists and coaches in these schools were perceived as having a different primary role by their principals and reported as essential to leading literacy instructional 
and professional development efforts in schools, is worth investigating and corroborating across other contexts.

Second, in what ways do the sources of funding effect the roles and presence of specialized literacy professionals? Schools in this study received funding that enabled them to support specialized literacy professionals if they chose to do so. We wonder whether schools that must use their hard money budget would choose to spend it on this resource? Given this state's grant funding cycle is complete, they are currently being faced with these personnel and funding decisions. Further, in what ways do state policies affect the role of these two distinct groups across states? While there is some evidence from past research (Author, 2015; Coburn \& Woulfin, 2012; Deussen, Coskie, Robinson, \& Autio, 2007) to suggest that state and federal grants do influence the roles of specialized literacy professionals, studies of principals' perceptions of specialized literacy professionals across states might be helpful in better understanding the national landscape.

Third, as mentioned above, the notion of overlapping roles emerged in our study, and mirrors some of the confusion that has existed in the research, policy, and practice literatures for at least the past twenty years. Research that focuses on the extent of existing overlap and whether such overlap is productive, and when it is simply confusing to teachers and school leaders, would be helpful to the field.

Finally, while this study identified the possibilities for collaboration between the principal and specialized literacy professionals, the exact nature of that collaboration is an area for additional investigation using other methodologies. The interactions between principals and these informal literacy leaders makes a difference in how successful they are in their work and in overall school literacy achievement. 
We recognize the limitations of survey research and plan to follow up with individual principals and specialized literacy professionals to further understand the exact nature of their work and how these professionals collaborate to lead literacy teaching and learning efforts in schools. The fields of literacy, coaching, and professional development research would be well served by multiple researchers conducting similar nuanced studies of the roles, responsibilities, and influence of specialized literacy professionals. We are particularly eager to see both more quantitative descriptive studies, as well as detailed qualitative cases of how specialized literacy professionals work collaboratively with school leadership.

\section{Implications for Policy and Practice}

Beyond the need for further research, we also see possible implications for preparing specialized literacy professionals. Our study, coupled with the Standards 2017, suggests that preparation programs need to be clearer about the differing roles of specialists and coaches. Reading/literacy specialists need more and better course- and fieldwork focusing on how to effectively assess and instruct students, as well as in how to support teachers in doing the same. Meanwhile, future coaches need similar coursework, but they also need more advanced preparation in designing, leading, and evaluating adult professional learning experiences. Our study suggests that coaches are more often asked (and expected) to lead schoolwide literacy initiatives and collaborate closely with principals. At this point in time, there is little to suggest that preparation programs are offering opportunities for future coaches to engage in such work during their graduate school experiences. Furthermore, in programs designed to prepare principals and specialized literacy professionals, more opportunities might be created for crossprogram collaborations (e.g., these preparation programs coming together for shared 
experiences) to prepare future principals and specialized literacy professionals for the kinds of collaboration that may determine success in their future school roles.

In addition to implications for preparing literacy professionals, the results of the study suggest that principals and specialized literacy professionals in schools can improve teaching and learning if they develop strategies that enable them to divide and conquer the great deal of student-, teacher-, and school-level work that must be done. This requires a clear delineation of roles and responsibilities. Too often, principals, specialists, and coaches organize their time in ways that do not efficiently support the improvement of literacy teaching and learning (Deussen, et al., 2007; Smith, 2007). The classic case is coaches being asked to spend more of their time on administrative tasks (e.g., organizing standardized testing efforts) rather than working directly with teachers on improving their instruction. Further, there is a need for ongoing communication among all professionals (e.g., bi-monthly literacy leadership team meetings where specialists report on student intervention work, coaches report on professional development and schoolwide literacy efforts, and principals reiterate yearlong goals for literacy improvement).

Finally, our study highlights some disconnects between what the literacy research community values as important and what specialized literacy professionals in this study are currently doing in schools, both elementary and secondary. For instance, principals in our study reported that few of their specialized literacy professionals across grade levels were "supporting teachers in the academic disciplines." We find this a bit surprising, given the major emphasis on disciplinary literacy across grade levels that has emerged over the past decade. In the annual international survey, "What's Hot in Literacy: 2017" (ILA, 2017), disciplinary literacy was once again rated as "very hot / extremely hot" by most of the participating researchers and practitioners. Moreover, the Common Core State Standards (NGA/CCSSO, 2010), have 
foregrounded literacy in the academic disciplines. This may be an area that warrants further investigation, and in some cases, principals may wish to think carefully about who in their schools may be best positioned to work as instructional leaders guiding disciplinary literacy efforts (e.g., perhaps content-area teacher leaders with specific literacy preparation).

\section{Limitations}

This study focused on a specific population of school principals in Pennsylvania who were participating in a federal literacy initiative, and thus the ways in which specialized literacy professionals functioned, and the responses of the principals to their work may differ from leaders of schools that have not received such funding. Although schools in the sample represented a wide variety of settings, with the largest numbers being either rural or urban/suburban with urban characteristics, there were few large cities in this sample. Further, we did not include results from those respondents who were not principals and acknowledge that those responses may have influenced results. At the same time, we feel confident that our intentional decision to focus on principals provided a more focused and analysis given that principals, with their evaluative responsibilities, have a distinct relationship with these professionals. Finally, the study focused on principals' perceptions of the roles of specialized literacy specialists and their perceptions may be different from those who serve as specialized literacy professionals. Likewise, this survey study did not result in descriptive information that would provide a more in-depth view of the roles of specialized literacy professionals; rather it provided a broad overview of a large sample of principals.

\section{Conclusion}

While there remains more work to be done to fully understand the national landscape of how principals perceive and work with specialized literacy professionals in their schools, this 
study helps extend the body of research describing and understanding the work of specialized literacy professionals and provides evidence that principals across grade levels valued their presence in schools. Principals viewed both specialists and coaches as integral to supporting teachers and students in literacy teaching and learning. At a point in time when funding for specialized literacy professionals in the United States continues to be at risk, this study encourages researchers, policymakers, and school leaders to redouble their efforts to invest time and energy into studying and supporting the work of literacy specialists and coaches as key supports to principals, teachers, and students. 


\section{References}

Allington, R.L. \& Shake M.C. (1986). Remedial reading; Achieving curricular congruence in classroom and clinic. The Reading Teacher, 39(7), 648-654, https://doi.org/10.1598/RT.60.2.10.

Author, 2001.

Author, 2002.

Author, 2003.

Author, 2009.

Author, 2012.

Author, 2015.

Author, 2017.

Berebitsky, D., Goddard, R.D. \& Carlisle, J.F. (2014). An examination of teachers' perceptions of principal support for teacher change and teachers' collaboration and communication around literacy in Reading First schools. Teachers College Record, 116(4), N/A.

Blamey, K.L., Meyer, C.K. \& Walpole, S. (2008). Middle and high school literacy coaches: A national survey. Journal of Adolescent and Adult Literacy, 52(4), 310-323, http://doi.org/10.14221/ajte.2013v38n4.1

Bryk, A.S., Sebring, P.B., Allensworth, F.E., Luppescu, S. \& Easton, J.A. (2010). Organizing schools for improvement. Lessons from Chicago. Chicago: University of Chicago Press.

Calo, K., Sturtevant, E., \& Kopfman, K. (2015) Literacy coaches’ perspectives of themselves as literacy leaders: Results from a national study of K-12 literacy coaching and leadership. Literacy Research and Instruction, 54(1), 1-18, http://doi.org/10.1080/19388071.2014.941050 
Camburn, E.M., Kimball, S. M. \& Lowenhaupt, R. (2008). Going to scale with teacher leadership: Lessons learned from a districtwide literacy coach initiative. In M.M. Mangin \& S.R. Stoelinga (Eds.), Effective teacher leadership: Using research to inform and reform. New York: Teachers College Press, 120-143.

Carlisle, J. \& Berebitsky, D. (2011). Literacy Coaching as a component of professional development. Reading and Writing: An Interdisciplinary Journal, 24(7), 773-800, http://doi.org/10.1007/s11145-009-9224-4

Coburn, C.E. \& Woulfin, S.L. (2012). Reading coaches and the relationship between policy and practice. Reading Research Quarterly, 47(1), 5-30, http://doi.org/10.1002/RRQ.008

Deussen, T., Coskie, T., Robinson, L., \& Autio, E. (2007). “Coach” can mean many things: Five categories of literacy coaches in Reading First (Issues \& Answers Report, REL 2007-No. 005). Washington, DC: U.S. Department of Education, Institute of Education Sciences, National Center for Education Evaluation and Regional Assistance, Regional Educational Laboratory Northwest. Retrieved from http://ies.ed.gov/ncee/edlabs/regions/northwest/pdf/rel_2007005.pdf

Dinham, S. (2005). Principal leadership for outstanding educational outcomes. Journal of Educational Administration, 43(4), 338-356, http://doi.org/10.1108/09578230510605405

Dole, J.A., Liang, L.A., Watkins, N.M. \& Wiggins, C.M. (2006). The state of reading professionals in the United States. The Reading Teacher, 60(2), 194-199, https://doi.org/10.1598/RT.60.2.10.

Eisold, K. (1997). The task of leadership: leadership as an attribute of group life. ADE Bulletin, 116, 33-37. 
Galloway, E.P., \& Lesaux, N.K. (2014). Leader, teacher, diagnostician, colleague, and change agent: A synthesis of the research on the role of the reading specialist in this era of RTIbased literacy reform. The Reading Teacher, 67(7), 517-526, http://doi.org/10.1002/trtr.1251

Goldenberg, C. (2004). Successful school change: Creating settings to improve teaching and learning. New York: Teachers College Press.

Heifetz, R., Grashow, A., \& Linsky, M. (2009). The practice of adaptive leadership: Tools and tactics for changing your organization and the world. Cambridge, MA: Harvard Business Press.

International Literacy Association. (2015a). The multiple roles of school-based specialized literacy professionals [Research brief]. Newark, DE: Author.

International Literacy Association. (2015b). The multiple roles of school-based specialized literacy professionals [Position statement]. Newark, DE: Author.

International Literacy Association. (2017). What's hot in literacy. Newark, DE: Author. Retrieved https://www.literacyworldwide.org/docs/default-source/resourcedocuments/whats-hot-2017-report.pdf?sfvrsn=59d7a78e_4

International Literacy Association (2018). Standards for the Preparation of Literacy Professionals 2017. Newark, DE: Author.

International Reading Association, (2006). Standards for middle and high school literacy coaches. New York, New York: Carnegie Corporation.

International Reading Association. (2010). Standards for reading professionals-Revised 2010. Newark, DE: Author. 
Kennedy, M., Birman, B.F., \& Demaline, R.E. (1986). The effectiveness of Chapter 1 services. Second Interim Report for the National Assessment of Chapter 1. Office of Educational Research and Improvement. United States Department of Education.

Louis, K.S., Leithwood, K., Wahlstrom,K.L. \& Anderson, S.E. (2010). Investigating the links to improved student learning: Final report of research findings. Minneapolis, MN: University of Minnesota.

Mangin, M. (2007). Facilitating elementary principals'support for instructional teacher leadership. Educational Administration Quarterly, 43(3), 319-357, http://doi.org/ $10.1177 / 0013161 X 07299438$

Mangin, M. M., \& Stoelinga, S. R. (Eds.). (2008). Effective teacher leadership: Using research to inform and reform. New York: Teachers College Press.

Marsh, J.A., McCombs, J.S., Lockwood, J.R., Martorell, F., Gershwin, D., Naftel, S., ... \& Crego, A. (2008). Supporting literacy across the sunshine state: A study of Florida middle school reading coaches. Santa Monica, CA: Rand Corporation.

Matsumura, L.C., Sartoris, M., Bickel, D., \& Garnier, H. (2009). Leadership for literacy coaching: The principal's role in launching a new coaching program. Educational Administration Quarterly, 45(5), 655-693, http://doi.org/10.1177/0013161X09347341

National Association of Secondary School Principals and National Association of Elementary School Principals. (2013). Leadership matters: What the research says about the importance of principal leadership. Reston, VG: Author.

National Governors Association Center for Best Practices \& Council of Chief State School Officers (NGA/CCSSO). (2010). The Common Core State Standards for English Language Arts \& Literacy in History/Social Studies, Science, and Technical Subjects. 
Appendix A: Research Supporting Key Element of the Standards. Washington, DC: Author.

Neumerski, C. (2013). Rethinking instructional leadership, a Review: What do we know about principal, teacher, and instructional leadership, and where should we go from here? Educational Administration Quarterly, 49(2), 310-347, http://doi.org/ $10.1177 / 0013161 X 12456700$

No Child Left Behind Act of 2001, P.L. 107-110, 20 U.S.C. § 6319 (2002).

Rush, L.S. (2013). Literacy coaching in Wyoming secondary schools. Journal of Literacy Research, 45(3), 267-294, http://doi.org/ 10.1177/1086296X13493039

Sebring, P.B. \& Bryk, A.S. (2000). School leadership and the bottom line in Chicago. Chicago, IL: Consortium on Chicago School Research.

Smith, A. T. (2007). The middle school literacy coach: Considering roles in context. 56th yearbook of the National Reading Conference (pp. 53-67). Oak Creek, WI: National Reading Conference.

Snow, C.E., Burns, M.S., \& Griffin, P. (1998). Preventing reading difficulties in young children. Washington, DC: National Academy Press.

Spillane, J.P. (20051). Distributed leadership. The Educational Forum, 69(2), 143-150, http://doi.org/10.1080/00131720508984678.

Spillane, J.P. (2015). Leadership and learning: Conceptualizing relations between school administrative practice and instructional practice. Societies, 5, 277-294. http://doi.org/10.3390/soc5020277. 
Spillane, J.P., Halverson, R. \& Diamond, J.B. (2001). Investigating school leadership practice: A distributed perspective. Educational Researcher, 30(3), 23-28, http://doi.org/ 10.3102/0013189X030003023

Supovitz, J., Sirinides, P., \& May, H. (2010). How principals and peers influence teaching and learning. Educational Administration Quarterly, 46(1), 31-56, http://doi.org/ $10.1177 / 1094670509353043$

Walp, T.P. \& Walmsley, S.A. (1989). Instructional and philosophical congruence: Neglected aspects of coordination. The Reading Teacher, 42(6), 364-368.

Walpole, S. \& Blamey, K.L. (2008). Elementary literacy coaches: The reality of dual roles. The Reading Teacher, 62(3), 222-231, http://doi.org/10.1598/RT.62.3.

Walpole, S. \& McKenna, M.C. (2012). The literacy coach's handbook: A guide to researchbased practice ( $2^{\text {nd }}$ ed.). New York: Guilford Press. 
Table 1

School Demographics

\begin{tabular}{|c|c|c|}
\hline Demographic & $\begin{array}{c}N \\
(N=103)\end{array}$ & $\begin{array}{c}\text { Overall } \\
\%\end{array}$ \\
\hline \multicolumn{3}{|l|}{ School Type } \\
\hline Elementary & 68 & 66 \\
\hline Secondary & 35 & 34 \\
\hline Title 1 & 71 & 69 \\
\hline \multicolumn{3}{|l|}{ Location } \\
\hline Urban & 12 & 12 \\
\hline Suburban w urban characteristics & 19 & 19 \\
\hline Suburban & 22 & 21 \\
\hline Small city in rural area & 21 & 20 \\
\hline Rural & 27 & 26 \\
\hline Other & 2 & 2 \\
\hline \multicolumn{3}{|l|}{ SES (\% free and reduced) } \\
\hline More than $90 \%$ & 17 & 17 \\
\hline $75-90 \%$ & 3 & 3 \\
\hline $50-74 \%$ & 34 & 33 \\
\hline $25-49 \%$ & 41 & 40 \\
\hline $10-24 \%$ & 8 & 8 \\
\hline \multicolumn{3}{|l|}{ Principal Experience } \\
\hline First Year & 15 & 15 \\
\hline $2-5$ & 50 & 49 \\
\hline $6-10$ & 26 & 25 \\
\hline $11-15$ & 0 & 0 \\
\hline More than 15 & 12 & 12 \\
\hline
\end{tabular}

Note: Total of percentages do not equal 100 for every category due to rounding. 
Table 2

Elementary and Secondary Schools with Specialized Literacy Professionals

\begin{tabular}{|c|c|c|c|c|c|c|}
\hline & \multicolumn{2}{|c|}{$\begin{array}{l}\text { All Schools } \\
\quad N=103\end{array}$} & \multicolumn{2}{|c|}{$\begin{array}{c}\text { Elementary } \\
n=68\end{array}$} & \multicolumn{2}{|c|}{$\begin{array}{c}\text { Secondary } \\
\quad n=35\end{array}$} \\
\hline & $n$ & $\%$ & $n$ & $\%$ & $n$ & $\%$ \\
\hline $\begin{array}{l}\text { Reading/Literacy } \\
\text { Specialist }\end{array}$ & 74 & 72 & 59 & 86 & 15 & 42 \\
\hline Coach & 77 & 75 & 49 & 72 & 28 & 80 \\
\hline $\begin{array}{l}\text { Reading/Literacy } \\
\text { Coordinator }\end{array}$ & 9 & 9 & 8 & 8 & 1 & 10 \\
\hline
\end{tabular}


Table 3

Engagement of Reading/Literacy Specialists and Coaches in High Frequency Activities

\begin{tabular}{|c|c|c|c|c|c|c|}
\hline & \multicolumn{2}{|c|}{ Specialists } & \multicolumn{2}{|c|}{ Coaches } & \multirow[b]{2}{*}{$X^{2}$} & \multirow[b]{2}{*}{$p$-value } \\
\hline & $n$ & $\%$ & $n$ & $\%$ & & \\
\hline Helping teachers understand data & 15 & 21 & 40 & 53 & $15.559^{\mathrm{a}}$ & $.000 *$ \\
\hline Instructing students & 52 & 70 & 33 & 43 & $11.007^{\mathrm{a}}$ & $.001 *$ \\
\hline $\begin{array}{l}\text { Co-planning and co-teaching with } \\
\text { classroom teachers }\end{array}$ & 19 & 27 & 38 & 50 & $7.617^{\mathrm{a}}$ & $.006^{*}$ \\
\hline $\begin{array}{l}\text { Working with principal to } \\
\text { organize/lead the literacy program }\end{array}$ & 16 & 22 & 29 & 39 & $4.677^{\mathrm{a}}$ & .031 \\
\hline Coaching teachers & 23 & 32 & 37 & 49 & $4.298^{\mathrm{a}}$ & .038 \\
\hline Assessing students & 29 & 40 & 37 & 49 & $1.382^{\mathrm{a}}$ & .240 \\
\hline $\begin{array}{l}\text { Supporting teachers in the } \\
\text { academic disciplines }\end{array}$ & 7 & 10 & 11 & 14 & $.515^{\mathrm{a}}$ & .473 \\
\hline $\begin{array}{l}\text { Providing professional learning for } \\
\text { groups of teachers }\end{array}$ & 23 & 32 & 24 & 32 & $.011^{\mathrm{a}}$ & .916 \\
\hline
\end{tabular}


Table 4

High Frequency Activities of Reading/Literacy Specialists at Elementary $(\mathrm{n}=59)$ and Secondary $(\mathrm{n}=15)$ Levels

\begin{tabular}{|c|c|c|c|c|c|c|}
\hline & \multicolumn{2}{|c|}{ Elementary } & \multicolumn{2}{|c|}{$\underline{\text { Secondary }}$} & \multirow[b]{2}{*}{$X^{2}$} & \multirow[b]{2}{*}{$p$-value } \\
\hline & $n$ & $\%$ & $\bar{n}$ & $\%$ & & \\
\hline Helping teachers understand data & 10 & 17 & 5 & 39 & $2.870^{\mathrm{a}}$ & .090 \\
\hline Instructing students & 45 & 75 & 7 & 50 & $3.396^{\mathrm{a}}$ & .065 \\
\hline $\begin{array}{l}\text { Co-planning and co-teaching with } \\
\text { classroom teachers }\end{array}$ & 15 & 26 & 4 & 31 & $.106^{\mathrm{a}}$ & .745 \\
\hline $\begin{array}{l}\text { Working with principal to } \\
\text { organize/lead the literacy program }\end{array}$ & 13 & 22 & 3 & 23 & $.007^{\mathrm{a}}$ & .935 \\
\hline Coaching teachers & 19 & 33 & 4 & 29 & $.091^{\mathrm{a}}$ & .763 \\
\hline Assessing students & 24 & 41 & 5 & 36 & $.116^{\mathrm{a}}$ & .733 \\
\hline $\begin{array}{l}\text { Supporting teachers in the } \\
\text { academic disciplines }\end{array}$ & 6 & 18 & 1 & 20 & $.010^{\mathrm{a}}$ & .922 \\
\hline $\begin{array}{l}\text { Providing professional learning for } \\
\text { groups of teachers }\end{array}$ & 20 & 35 & 3 & 23 & $.631^{\mathrm{a}}$ & .427 \\
\hline
\end{tabular}


Table 5

High Frequency Activities of Coaches at Elementary $(n=49)$ and Secondary $(n=28)$ Levels

\begin{tabular}{|c|c|c|c|c|c|c|}
\hline & \multicolumn{2}{|c|}{ Elementary } & \multicolumn{2}{|c|}{ Secondary } & \multirow[b]{2}{*}{$X^{2}$} & \multirow[b]{2}{*}{$p$-value } \\
\hline & $n$ & $\%$ & $n$ & $\%$ & & \\
\hline Helping teachers understand data & 26 & 53 & 14 & 52 & $.010^{\mathrm{a}}$ & .920 \\
\hline Instructing students & 23 & 47 & 10 & 37 & .695 & .405 \\
\hline $\begin{array}{l}\text { Co-planning and co-teaching with } \\
\text { classroom teachers }\end{array}$ & 24 & 48 & 14 & 52 & $.104^{\mathrm{a}}$ & .747 \\
\hline $\begin{array}{l}\text { Working with principal to } \\
\text { organize /lead the literacy program }\end{array}$ & 18 & 37 & 11 & 42 & $.222^{\mathrm{a}}$ & .637 \\
\hline Coaching teachers & 23 & 47 & 14 & 52 & $.168^{\mathrm{a}}$ & .682 \\
\hline Assessing students & 26 & 54 & 11 & 41 & $1.246^{\mathrm{a}}$ & .264 \\
\hline $\begin{array}{l}\text { Supporting teachers in the academic } \\
\text { disciplines }\end{array}$ & 8 & 24 & 3 & 30 & $.173^{\mathrm{a}}$ & .678 \\
\hline $\begin{array}{l}\text { Providing professional learning for } \\
\text { groups of teachers }\end{array}$ & 18 & 36 & 6 & 23 & $1.322^{\mathrm{a}}$ & .250 \\
\hline
\end{tabular}


Table 6

Perception of Specialized Literacy Professionals' Influence at Elementary $(n=68)$ and Secondary $(n=35)$ Levels

\begin{tabular}{|c|c|c|c|c|}
\hline \multirow[t]{3}{*}{ Area of Influence } & \multicolumn{4}{|c|}{ Moderate to Major Influence } \\
\hline & \multicolumn{2}{|c|}{$\begin{array}{l}\text { Elementary } \\
\text { Principals }\end{array}$} & \multicolumn{2}{|c|}{$\begin{array}{l}\text { Secondary } \\
\text { Principals }\end{array}$} \\
\hline & $n$ & $\%$ & $n$ & $\%$ \\
\hline Raising student achievement & 64 & 94 & 29 & 83 \\
\hline Improving instructional practices & 58 & 85 & 29 & 83 \\
\hline $\begin{array}{l}\text { Creating a culture of collaboration and } \\
\text { improvement }\end{array}$ & 60 & 88 & 31 & 89 \\
\hline Closing achievement gaps & 60 & 88 & 27 & 77 \\
\hline $\begin{array}{l}\text { Creating a vision for literacy teaching and } \\
\text { learning }\end{array}$ & 55 & 81 & 28 & 80 \\
\hline $\begin{array}{l}\text { Building and maintaining school/community } \\
\text { partnerships }\end{array}$ & 50 & 74 & 15 & 43 \\
\hline
\end{tabular}

